\title{
Múltiples caras fundidas en un solo rostro. Nación y trietnicidad en El hombre colombiano*
}

\author{
Roxana Ponce Arrieta 1 \\ Universidad Nacional Autónoma de México
}

ORCID: 0000-0002-8336-5771

Recibido: 11 de diciembre del 2019

Aceptado: 21 de febrero del 2020

\section{RESUMEN}

Este artículo examina la idea de nación y trietnicidad en El hombre colombiano de Manuel Zapata Olivella. Para ello divido el artículo en cuatro partes: 1) Analiza las causas del marginamiento de las obras antropológicas de este intelectual en los estudios críticos sobre su obra y realiza una revisión de estos estudios sobre las ideas de nación y mestizaje. 2) Expone la propuesta de Alejandro Araujo para el estudio de la nación, que consiste en el cruce de dos categorías de análisis: regímenes de historicidad y formación nacional de la alteridad, con el fin de definir la idea de Zapata Olivella sobre los sujetos o grupos que conforman la nación y cómo los coloca en términos temporales. 3) Analiza las razones que llevaron a este intelectual a examinar la autenticidad de la nación colombiana, enfocándose en sus nociones de neocolonialismo, esquizofrenia cultural, cultura alienada y auténtica. 4) Finalmente, examina sus ideas de nación y la trietnicidad en este ensayo. La trivialización y la periferización de lo "afrodescendiente" explican la marginación de las obras antropológicas en los estudios críticos. La redefinición de la nación en El hombre colombiano se sitúa en el análisis de las implicaciones culturales de la dependencia económica en Colombia y el mestizaje explica la formación histórica de la nación, sus orígenes, su constitución y los grupos que la integran.

Palabras clave: Cultura nacional, trietnicidad, neocolonialismo, esquizofrenia cultural, El hombre colombiano.

\begin{abstract}
This article analyzes the idea of nation and trietnic population in The Colombian man by Manuel Zapata Olivella. It is divided into four parts: 1) it inquiries the causes of marginalization in this scholar's anthropological works on critical analysis about his research and looks over this investigation about the concepts of nation and miscegenation. 2) It presents Alejandro Araujo's proposal on the study of nation which consists of the interchange between 2 analyzing categories:
\end{abstract}

* Multiple faces fused into one face. Nation and triethnicity in The Colombian Man

'Pasante en la Maestría en Estudios Latinoamericanos por la Universidad Nacional Autónoma de México. Su tesis versa sobre las ideas de nación, mestizaje y africanidad en El hombre colombiano de Manuel Zapata Olivella. Correo electrónico: ro_xi_la@hotmail.com 
historicity regimes and national formation of otherness with the objective of defining Zapata Olivella's idea about the subjects and groups which embody the nation and how they are categorized in temporary terms. 3) It scrutinizes the reason which led this scholar to examine the authenticity of the Colombian nation. It focuses on his notion of neo-colonialism, cultural schizophrenia, and alienated authentic culture. 4) Lastly, it explores his ideas of nation and trietnic population. The trivialization and peripheralization of Afro-descending explain the marginalization of the anthropological works on critical analysis; the redefinition of the nation in El Hombre Colombiano in the analysis of cultural implications of economic dependence in Colombia as well as miscegenation explains its historical formation, its origins, its constitution, and the groups which embody them.

Keywords: Nacional culture, three-ethnicity, neocolonialism, schizophrenia cultural, The Colombian man.

\section{INTRODUCCIÓN}

Manuel Zapata Olivella es una de las figuras intelectuales afrocolombianas más importantes del siglo XX. Su obra multifacética abarca obras literarias, proyectos folclóricos e investigaciones antropológicas. Asimismo, fue un intelectual preocupado no sólo por valorar e investigar las contribuciones culturales de la diáspora africana en su país y en América, sino también por analizar otros temas como la nación, el folclor nacional, la literatura nacional, el racismo y la discriminación racial en Colombia.

La mayoría de los análisis críticos sobre Manuel Zapata Olivella se enfocan en su vasta producción literaria, lo cual contrasta con la poca atención que despiertan sus investigaciones y ensayos antropológicos. Entre sus principales obras antropológicas se encuentran: Tradición oral y conducta en Córdoba (1972), El hombre colombiano (1974), Etnografía colombiana (1984), Las claves mágicas de América Latina (1989), Enciclopedia audiovisual de la identidad colombiana: su lengua, su historia, su filosofía, sus costumbres y sus artes en un solo rostro (1989), La rebelión de los genes. El mestizaje americano en la sociedad futura (1997), y El árbol brujo de la libertad. África en Colombia. Orígenes. Transculturación. Presencia. Ensayo histórico mítico (2002), entre otras.

Para George Palacios, el proceso de formación intelectual de Manuel Zapata no se reduce a su faceta literaria sino que incluye otras esferas intelectuales, como la investigación folclórica y antropológica. Asimismo, se interesó por temas políticos y económicos, que no estaban desvinculados de sus reflexiones sobre la cultura nacional, el folclor y el colonialismo cultural:

[...] su proceso de formación intelectual no se restringe a la cultivación de lo literario a secas que, debe reiterarse, en su contexto nacional se definía por el cultivo de "las bellas formas consagradas", sino que enlaza a problemáticas de larga duración que hacen de su rol y condición de intelectual racializado una perspectiva de análisis crítica a la problemática de la 
existencia de este tipo de intelectual en el contexto colombiano y latinoamericano. (Palacios, 2015: 442)

En este sentido, Elena Oliva sugiere situar históricamente la configuración de estos intelectuales

y la formación de su pensamiento, pues sus perfiles específicos ofrecen una serie de perspectivas teóricas sobre los procesos históricos, culturales y económicos de la región latinoamericana, cuyas propuestas han sido ignoradas por las academias latinoamericanas. Acerca de esta propuesta, Oliva precisa que

No obstante la especificidad que los caracteriza y les entrega un determinado perfil, es importante considerar que tanto la configuración de estos intelectuales como el desarrollo que ha tenido su pensamiento, no puede desligarse del curso histórico de la región. No sólo su origen está vinculado a los procesos de modernización latinoamericana, sino que sus propias reflexiones están en constante diálogo con las transformaciones económicas, políticas y sociales por las que ha atravesado América Latina. (Oliva, 2017: 61)

Este artículo busca reflexionar acerca del pensamiento de Manuel Zapata Olivella sobre la nación y el mestizaje, partiendo del supuesto de que estas ideas presentaron transformaciones en distintos momentos de la trayectoria de este intelectual. Se eligió El hombre colombiano debido a que en él se condensan estas ideas que se venían desarrollando desde la década de 1940, y se desarrollan sus ideas sobre neocolonialismo, esquizofrenia cultural y cultura alienada. Para ello divido el texto en cuatro partes: 1) Me enfoco en examinar por qué la literatura antropológica de este autor tiene un lugar marginal en las investigaciones y estudios críticos sobre su obra. Asimismo, ofrezco un estado del arte sobre los conceptos de nación y trietnicidad en la obra de Zapata Olivella. 2) Expongo la propuesta teórica de Alejandro Araujo para el estudio de la nación, que consiste en el cruce de dos categorías de análisis, regímenes de historicidad y formación nacional de la alteridad, con el objetivo de definir la visión del intelectual colombiano sobre los sujetos o grupos que conforman la nación y cómo los coloca en términos temporales en El hombre colombiano. 3) Analizo las razones que llevaron a este intelectual a examinar la autenticidad de la nación colombiana, enfocándome principalmente en su noción de neocolonialismo, esquizofrenia cultural y cultura alienada. 4) Finalmente, examino su idea sobre la nación colombiana y la trietnicidad. En esta parte enfatizo sus principales características.

\section{La marginalidad de las investigaciones sobre las obras antropológicas de Zapata Olivella}

En 1974, Manuel Zapata Olivella asistió al Coloquio de la Negritud y América Latina, realizado en enero en Dakar, Senegal y publicó su obra titulada El hombre colombiano en la Enciclopedia del Desarrollo Colombiano, colección de Los fundadores. Este año representa un parteaguas en su trayectoria intelectual. Por un lado, su participación en el Coloquio en Dakar influyó de manera 
central en su activismo político afrodiaspórico, principalmente en su interés por incentivar redes entre los políticos e intelectuales de la diáspora africana. ${ }^{2} \mathrm{Y}$, por el otro, en su libro El hombre colombiano, Zapata Olivella condensaba una serie de ideas sobre la cultura nacional, la trietnicidad y la africanidad que había desarrollado en algunos artículos publicados en revistas y periódicos, así como en sus grupos y proyectos folclóricos, realizados junto con su hermana Delia Zapata Olivella.

Sin embargo, el interés de Manuel Zapata Olivella por la cultura nacional, la trietnicidad y la africanidad se puede rastrear desde la década de 1940, en sus artículos periodísticos dedicados a las músicas y danzas populares del Caribe colombiano, donde desarrolló sus primeras ideas sobre estos conceptos. Estas preocupaciones lo llevaron a realizar investigaciones sobre las músicas y danzas populares en el Caribe colombiano (1948-1952) y el Pacífico colombiano (1954), que le sirvieron para organizar, junto con Delia Zapata, dos grupos folclóricos con los que realizaron algunas giras por Colombia y otros países de América, Europa y Asia. De igual manera, participó en la organización de la Junta Nacional de Folclor (1964), fundó y dirigió por algunos años la revista Letras Nacionales (1965) y participó en el Primer Congreso de Cultura Nacional Colombiana (1966). También, realizó algunas estancias de investigación en su región de origen para elaborar su libro titulado Tradición oral y conducta en Córdoba (1972).

Lo nacional y la trietnicidad fueron temas centrales en su activismo político y cultural desde la década de 1940 hasta la publicación en 1989 de su Enciclopedia audiovisual de la identidad colombiana. No obstante, la mayoría de los estudios críticos sobre su obra se enfocan en su vasta producción literaria, que contrasta con el poco interés que despiertan sus ensayos antropológicos. Esta situación marginal de sus obras antropológicas provoca una serie de cuestionamientos: ¿Es casual o intencional este desinterés académico? ¿Cuáles son las razones que explican la ausencia de estos estudios?

En los últimos quince años, en los estudios afrocolombianos ha irrumpido y se ha desarrollado una línea de investigación sobre los intelectuales "negros", afrocolombianos y afrodescendientes", una de cuyas preocupaciones centrales es analizar las causas que explican la ausencia de investigaciones sobre estos intelectuales. Algunos autores como Santiago Arboleda Quiñones y José Antonio Caicedo Ortiz se han esforzado por conceptualizar las políticas de conocimiento

\footnotetext{
${ }^{2}$ Una de las repercusiones de este Coloquio en la trayectoria de Zapata Olivella fue la organización y participación de tres Congresos de la Cultura Negra de las Américas. El primer Congreso se realizó en 1977, en Cali, Colombia, organizado por el Instituto de Estudios Afro-Peruanos, la Fundación Colombiana de Investigaciones Folclóricas y el Centro de Estudios Afrocolombianos. El segundo Congreso titulado "Identidad Cultural del Negro en las Américas", se realizó en Panamá, en 1980, presidido por el sociólogo y poeta Gerardo Maloney y organizado por el Centro de Estudios Panameños. El tercer Congreso titulado "Diáspora africana: conciencia política y cultura africana", presidido por el poeta, sociólogo y político Abdias Do Nascimento, fue realizado en São Paulo, Brasil, en 1983.

${ }^{3}$ A lo largo de esta parte del texto uso las tres categorías identitarias debido a que los estudios sobre estos intelectuales usan una o las tres categorías, aunque hay que aclarar que cada una tiene trayectorias históricas y significados diferentes, por lo que su uso en el texto es consciente de estas diferencias y no se usarán como sinónimos. En los otros apartados, uso las terminologías empleadas por Manuel Zapata Olivella en sus textos, principalmente la de "negro", siempre entrecomillado, con lo que distingo el empleo de esta por el autor.
} 
y prácticas académicas que marginaron e ignoraron estas tradiciones intelectuales en los estudios afrocolombianos y en la academia colombiana. De acuerdo con sus planteamientos, ambos coinciden en que esta ausencia no es resultado de acciones involuntarias, sino que obedece a una política de exclusión académica, de allí que analicen un repertorio de prácticas académicas que imposibilitaron la emergencia de esta línea de investigación.

A partir de su postura teórica y política decolonial, Santiago Arboleda afirma que la antropología y la historia académica colombiana configuraron un patrón de clandestinización pública de los pensamientos y las agencias intelectuales afrocolombianas. Para el autor, esta exclusión y negación de la tradición intelectual afrocolombiana es resultado de la colonialidad del poder, en su dimensión de la colonialidad del saber, que se define como una serie de discursos y prácticas que consideran a Occidente como epistémicamente superior a otras formas de pensamiento. De allí que sostenga que el eurocentrismo que operó en las ciencias sociales y humanas colombianas clandestinizó los pensamientos afrocolombianos a través de cuatro prácticas académicas: el escamoteo, la tribalización, la trivialización y la invisibilización (Arboleda, 2011: 6). ${ }^{4}$

Por su parte, el sociólogo afrocolombiano José Antonio Caicedo Ortiz se cuestiona la ausencia de estudios históricos sobre los intelectuales "negros" y afrocolombianos y retoma el concepto de invisibilidad de Nina S. de Friedemann para explicar este vacío. Refiere cómo el concepto fue empleado por Friedemann para definir el patrón ideológico que operó en la antropología para negar sistemáticamente la presencia y la contribución de los africanos y sus descendientes en la nación. De esta manera, Caicedo busca aportar elementos para la comprensión de la invisibilidad de los intelectuales negros y afrocolombianos en el campo de la historia.

Por tanto, el autor pretende llenar de contenido la categoría de invisibilización con el objetivo de analizar el funcionamiento de este dispositivo y sus consecuencias. Para no caer en generalizaciones plantea cuatro mecanismos que explican la ausencia de estudios sobre el activismo político e intelectual "negro" y afrocolombiano: 1) Ausencia afrodescendiente en la memoria nacional. 2) Despolitización de los sujetos negros en las narrativas. 3) Representación periférica de lo afrodescendiente. 4) La fragmentación del tiempo histórico (Caicedo, 2013: 41-46). ${ }^{5}$

\footnotetext{
${ }^{4}$ Santiago Arboleda define al escamoteo del pensamiento afrocolombiano como una práctica académica a la que definió como "la mutilación de la agencia histórica". Es decir que algunos estudios dedicados a estas poblaciones incluyeron el tema de las resistencias pero minimizaron o excluyeron su pensamiento político. A "la tribalización" la define como la práctica académica de incomprensión y negación de las racionalidades políticas de los descendientes de africanos, por lo que considera que se construyeron nuevas imágenes del "salvaje" y la "tribu". A "la trivialización" la caracteriza como una práctica académica de deslegitimación o banalización de los pensamientos de estos grupos, los cuales son señalados como locales, folclóricos y racistas. Finalmente, "la invisibilización" es definida como una práctica académica vinculada al escamoteo de los pensamientos sobre esta población, debido a que esta última constituye un terreno de invisibilización de sus pensamientos.

${ }^{5}$ Este autor define a "la ausencia afrodescendiente en la memoria nacional" como el mecanismo a través del cual las élites políticas y culturales excluyeron a estas poblaciones de los relatos nacionales hegemónicos. Al segundo mecanismo lo denomina "la despolitización de los sujetos negros", lo cual consiste en la eliminación y negación de sus demandas y agendas políticas como consecuencia de las narrativas históricas hegemónicas basadas en modelos de racialización y racialismo. El tercer mecanismo, denominado "la periferización de lo afrodescendiente", es una consecuencia de estas narrativas histórica hegemónicas que elaboraron representaciones negativas sobre las geografías y las poblaciones descendientes de africanos. Finalmente, el último mecanismo, denominado "la fragmentación del tiempo histórico", consiste en que la mayoría de los estudios anclan a estos sujetos a determinados períodos y a condiciones de subordinación, como al período colonial y a la condición de esclavizados, y no ofrecen análisis con una perspectiva de larga duración sobre estas poblaciones.
} 
Sin embargo, aunque Arboleda y Caicedo han resaltado las facetas de Zapata Olivella como investigador del folclor y de la antropología, ninguno ha profundizado en alguna de sus obras antropológicas, más bien sus estudios continúan enfocándose en sus obras literarias. Por otra parte, Eduardo Restrepo y Pedro Velandia señalan a Manuel Zapata Olivella, junto con Aquiles Escalante y Rogerio Velásquez, como uno de los pioneros de los estudios afrocolombianos. Principalmente resaltan dos de sus obras: El hombre colombiano (1974) y Etnografía colombiana (1984). Sin embargo, en el campo de los estudios afrocolombianos no existe tampoco ningún estudio sobre la vasta producción antropológica de nuestro autor (Velandia, 2017: 165).

A la luz de estos esfuerzos por conceptualizar las políticas de conocimiento y prácticas académicas que marginaron estas tradiciones intelectuales, se puede afirmar que las obras antropológicas de Zapata Olivella han sido clandestinizadas por los estudios afrocolombianos y el establecimiento académico colombiano, a través de una serie de prácticas como la trivialización o banalización de sus argumentos antropológicos, por no tener una formación académica sino autodidacta en antropología. O también por el mecanismo de representación periférica de lo afrodescendiente, que establece una serie de estereotipos e imágenes negativas sobre las poblaciones y geografías mayoritariamente afrocolombianas, como el Caribe colombiano, que niegan a estos sujetos y espacios como productores de pensamiento.

La pregunta por la ausencia de estos estudios se extiende a la academia norteamericana, donde investigadores como Richard Jackson, Marvin Lewis y Laurence Prescott iniciaron los primeros estudios sobre la literatura de Manuel Zapata Olivella y otros escritores "negros" o "afrocolombianos", como Jorge Artel y Arnoldo Palacios. Siguiendo a Silvia Valero (2013), este grupo de investigadores estadounidenses se interesó en la literatura de escritores "negros" de habla hispana por una serie de factores políticos y académicos propios, entre los que se encuentran el nacionalismo negro, la creación de departamentos de Black Studies y la influencia del afrocentrismo como marco teórico-metodológico (18). Si bien estos estudios no se interesaron en la literatura antropológica de Manuel Zapata Olivella, considero que esta ausencia no respondió a las prácticas de invisibilización de la academia colombiana, sino que su interés estaba puesto en dar espacio y reconocimiento a estos intelectuales "negros" o afrocolombianos, focalizándose en sus facetas literarias cuyas obras eran poco reconocidas y estudiadas en la academia colombiana.

Cabe preguntarse entonces ¿cuáles serían las posibles razones que explicarían la invisibilidad de las obras antropológicas de Zapata Olivella en los estudios de estos críticos literarios estadounidenses? Desde mi perspectiva, considero que dicho desinterés se debe a la formación disciplinar de los investigadores, la cual imposibilitó que profundizaran en las obras de corte antropológico de nuestro autor, o que indagaran sobre las conexiones entre la literatura y la antropología en sus obras, como en Changó, el gran putas, a pesar de que el mismo autor sostuviera que la saga fue producto de una larga investigación histórica, antropológica, lingüística y psicológica, que realizó durante casi dos décadas. 
Roxana Ponce Arrieta

Por otra parte, si bien la mayoría de estudios críticos se enfocan en la obra literaria de Zapata, existen algunos análisis que se aproximan a las ideas de nación, trietnicidad y folclor. A continuación, ofreceré un breve panorama de los estudios que se han realizado sobre estos conceptos.

El historiador cartagenero Alfonso Múnera realizó una compilación de los artículos de Zapata Olivella publicados en distintas revistas y periódicos de distintos países, titulada Por el sendero de sus ancestros: textos escogidos 1940-2000. En su introducción "La nación inclusiva" ofrece un análisis de las interpretaciones de Zapata sobre el nacionalismo literario, el colonialismo cultural, su defensa del arte y la cultura popular, su denuncia del racismo y la exaltación de lo negro y lo indio en la valorización de la cultura colombiana, entre otros temas (Múnera, 2010: 11-43). Cabe destacar que este historiador considera a Zapata como uno de los pioneros en colocar el término raza como categoría analítica de la realidad colombiana. Sin embargo, considero que no existe una profundización en el análisis de este concepto y sus cambios a lo largo de sus obras literarias, folclóricas y antropológicas.

En la misma línea, George Palacios, en su texto "Apuntes sobre la música, el folclor, lo nacionalpopular y la literatura en algunos de los escritos tempranos de Manuel Zapata Olivella” (2015), examina los procesos que fundamentan el pensamiento de este intelectual alrededor de la diáspora africana en general y de Colombia en particular. Una de sus tesis centrales es que en los textos recopilados por Múnera existen algunas ideas que van a constituir su imagen de nación sobre los aportes de los africanos y sus descendientes, la cual se va a oponer a los proyectos de nación creados por las élites culturales y políticas del s. XIX y XX en Colombia (439-470).

Por su parte, la antropóloga Mara Viveros Vigoya, en su artículo “Mestizaje, trietnicidad e identidad negra en la obra de Manuel Zapata Olivella” (2013), se enfoca en explorar estos tres conceptos en varios ensayos, artículos y novelas a partir de los cuales señala algunos rasgos que definen la concepción del escritor sobre el mestizaje como proceso biológico, cultural, heterogéneo y conflictivo. Asimismo subraya algunas de las ambigüedades y contradicciones de su visión del mestizaje (87-103).

También encontramos el texto de Santiago Arboleda titulado "El mestizaje radical de Manuel Zapata Olivella: raza, etnia y ciudadanía" (2010), en el cual, a partir del estudio de los debates de los tres Congresos de Cultura Negra de las Américas y algunos ensayos del escritor, examina sus ideas en torno a los límites de la democracia colombiana ante la presencia del racismo y la discriminación. Sostiene, además, que su idea de mestizaje es una propuesta antirracista radical en tanto lo reconoce como un hecho universal de la humanidad (441-461).

Uno de los textos centrales en la comprensión de la concepción sobre la nación y el mestizaje en la obra de Zapata Olivella es la tesis de Catalina Zapata Cortés (2009), titulada Entre danzas, tambores y rezos. Somos colombianos. Representaciones de lo "negro" en la obra folclórica de Manuel y 
Delia Zapata Olivella (1950-1970), donde analiza el terreno discursivo de estas representaciones conformado por las políticas educativas de la República Liberal y enfatiza en que estos pensadores liberales concibieron el folclor nacional como resultado del mestizaje, cuyo principal protagonista fue el "pueblo". Esta autora sostiene que la reivindicación que hizo Zapata Olivella de lo "negro" sirvió para explicar la diversidad folclórica regional, y que configuró una representación sobre los africanos y sus descendientes como mártires y héroes de la nación (57-88).

Después de ofrecer un panorama de los estudios sobre las ideas de nación y el mestizaje de Manuel Zapata, considero necesario avanzar en estudios interdisciplinarios que incluyan lo literario, lo folclórico y lo antropológico y que tengan una perspectiva de larga duración que permita identificar las transformaciones del pensamiento de Zapata sobre estos conceptos. Esto podría contribuir a comprender qué entendía por raza, etnia, identidad nacional y trietnicidad en los distintos momentos de su trayectoria. Por tanto, el presente artículo busca contribuir a reflexionar sobre la nación y el mestizaje triétnico en El hombre colombiano, ensayo antropológico en el que condensa una trayectoria de debates y reelaboraciones sobre dichos conceptos que se remonta a la década de 1940.

\section{Aproximación teórica: regímenes de historicidad y formación nacional de la alteridad}

El historiador mexicano Alejandro Araujo (2015) sugiere el cruce dos categorías de análisis para examinar cómo el mestizo se convirtió en el grupo nacional, el mestizaje como el proceso fundacional de la nación mexicana y cómo el mestizaje generó un lugar particular de "lo indígena": el régimen de historicidad y la formación nacional de alteridades. A partir de la historia conceptual, Araujo ofrece un panorama de las condiciones de posibilidad que contribuyeron en la formulación de las dos nociones y las cuestiones que hicieron evidentes. La noción del régimen de historicidad surgió después de la Segunda Guerra Mundial, como resultado del cuestionamiento a la noción moderna de la historia. Esta noción planteó a la historia como un movimiento hacia el progreso. Araujo retoma la categoría de régimen de historicidad para analizar las formas en las que un grupo o una sociedad se conciben a sí mismos en términos temporales, es decir su relación con el pasado, el presente y el futuro (162-165).

Por otra parte, la noción de formación nacional de la alteridad es resultado de un largo proceso de cuestionamientos sobre el concepto de nación, que datan desde fines del siglo XIX hasta fines del siglo XX. Según Araujo, Ernest Renan inició la fase de cuestionamiento de la noción genealógica de la nación a fines del siglo XIX. Ante la idea de que la nación era producto de una historia y con atributos objetivos (como la lengua, la religión, la raza, costumbres, entre otras), Renan plantea que para que exista una nación es necesario la voluntad y el deseo de formar parte de esta comunidad, es decir su dimensión subjetiva, y, cuestiona el lugar de los atributos objetivos de ella, debido que existen naciones que no cuentan con ninguno de ellos o existen otros grupos que los tienen pero no se reconocen como tales (166). 
Roxana Ponce Arrieta

Otro momento importante que posibilitó la formulación del concepto de formación nacional de la alteridad fueron los esfuerzos por historizar el surgimiento, invención, construcción y formación de la nación en los años setenta, los cuales pusieron en entredicho la noción genealógica de la nación al sostener que no era una entidad natural sino que tenía una historia. De este modo la nación se convirtió en objeto de atención histórica. Para estas posturas, era importante estudiar no sólo las representaciones, símbolos y atributos de la nación, sino los instrumentos a través de los cuales se les inculcaron el sentido de pertenencia a esta comunidad (Araujo, 2015: 167).

Para Araujo, la categoría de formación nacional de la alteridad tiene implícitas las críticas a la noción genealógica de la nación y parte de la importancia del nivel subjetivo para la existencia de la nación. Esta noción introdujo, al tema de la formación de la nación, el problema sobre los grupos que integraban la misma. En el proceso de revisión histórica de la construcción de las naciones se dejó entrever que existían grupos, como los “indígenas" o los "negros", entre otros más, que no estaban representados en las historias nacionales ni en otras formas de representación (168).

En este marco, Araujo retoma el concepto de alteridades históricas de la argentina Rita Segato, para denominar la producción de las diferencias y alteridades en los procesos de configuración de la nación. Para Segato, ciertos grupos eran identificados por el discurso oficial como los “otros" de la nación, por tanto la nación operó como un régimen de alterización y estableció un orden de jerarquías para colocar a las diferencias que producía. Para el caso latinoamericano, las naciones otorgaron un lugar diferente a "lo indígena" y a lo "negro", los cuales adquirieron diferente significado y posición en cada país de la región. La categoría de formación de la alteridad nacional permite examinar el modo en que se inculcaron las diferencias. Al respecto, Araujo comenta:

[...] si la cuestión nacional quería saber cómo es que se había generado el sentimiento de semejanza entre los miembros de la nación, la cuestión de la alteridad nacional, de las diferencias en la nación, introduce la pregunta por el modo en que se marcaron esas diferencias.

Se trata de saber quiénes fueron marcados como otros, con qué criterios se decidió que fueran y no fueran parte de la nación, qué estatuto legal, político y social implicaba esa diferenciación, cómo se explicaba o justificaba la diferencia, qué se pensaba hacer con ella, para qué y para quién no era evidente. (172)

Por consiguiente, el investigador mexicano sugiere articular las nociones de regímenes de historicidad y formación nacional de la alteridad para analizar las formas en que se elaboraron y representaron las diferencias en los procesos de conformación de la nación, en especial los grupos "indígenas" y "negros", y cómo fueron colocados estos grupos en términos temporales, es decir en relación con el pasado, presente y futuro de la nación. De allí que considero pertinentes ambas categorías para examinar en El hombre colombiano las formas de representación de la nación, los grupos que la integran y cómo son colocados temporalmente. 


\section{III: La negación de la autenticidad de la cultura nacional: neocolonización, dependencia tecnológica y esquizofrenia cultural}

En el presente apartado se pretende responder a las siguientes interrogantes: ¿Por qué Manuel Zapata buscó examinar y reevaluar el proceso de conformación de la nación? ¿Cuáles son las razones de su presente que lo llevaron a redefinir la historia de la cultura nacional? ¿Por qué considera que la afirmación de la autenticidad y la originalidad de la nación colombiana es un acto de descolonización?

Desde su presente, Zapata Olivella planteó que en Colombia existía una situación de neocolonización a nivel económico y cultural. La relación de dependencia tecnológica de Colombia con los países metropolitanos se expresó no sólo en la economía sino también en la cultura, que se manifestó en lo que denominó como esquizofrenia cultural del estrato académico o tecnológico ${ }^{6}$, que consistía en la adopción acrítica de patrones culturales y tecnológicos producidos en las metrópolis (Zapata Olivella, 1993: 151-155). De acuerdo con Zapata Olivella, este estrato exaltaba los patrones culturales extranjeros como auténticos y negaba la originalidad de la cultura colombiana, en especial la creatividad cultural del estrato tradicional, empírico o folclórico. Aunque ya no tenían contactos culturales forzados y violentos como en la conquista y la colonización, continuaban siendo impuestos por las metrópolis a través de otros mecanismos. Para definir este tipo de contactos culturales que ocurrían en la segunda mitad del s. XX, Zapata retomó la clasificación de Roger Bastide:

[...] según nuestros criterios, dice [refiriéndose a Bastide], existen tres tipos de contacto: los "libres", los contactos "forzados" -sobre los cuales la situación colonial nos proveería el mejor ejemplo- y, por último, los contactos "planificados".

Estos últimos corresponderían a la situación neocolonizadora, en la que los valores foráneos se fabrican y planifican en unas cuantas metrópolis para ser "impuestos" técnicamente a nuestro país mediante interventores criollos. (Zapata Olivella, 1974: 178)

En este sentido, el autor consideraba que la esquizofrenia cultural de este estrato sociocultural tenía un origen colonial, debido a que en dicho período los colonizadores negaron la creatividad cultural de “indígenas” y africanos para justificar su opresión y dominación. Por tanto, en la segunda mitad del siglo XX se encontraban resabios coloniales en la mentalidad del estrato académico o tecnológico

\footnotetext{
${ }^{6}$ Cabe aclarar que el autor no usa el término estrato como actualmente se utiliza en Colombia, es decir como estrato socioeconómico que clasifica los inmuebles domiciliarios para establecer los subsidios y las contribuciones por servicios públicos. Para Zapata Olivella, la sociedad colombiana estaba constituida por dos estratos socioculturales superpuestos y en interacción. Al primero lo define como estrato académico o tecnológico que históricamente ha subordinado al segundo estrato, tiene el control tecnológico, se nutre del sistema educativo formal y tiene bajo su disposición los recursos económicos y políticos para sobrevivir y producir. El segundo, denominado tradicional, empírico o folclórico, integrado por los "tipos raciales" ("negros", "mestizos", "indios", "mulatos", "zambos" y "blancos") y por los sectores analfabetas y semiletrados, que han sido históricamente oprimidos y expoliados por el primero, sobrevive a expensas de los conocimientos filosóficos y empíricos preservados en las culturas de los "tipos raciales", enriquecidas o empobrecidas por las técnicas del estrato dominante. El autor usa estas terminologías raciales para definir una serie de diferencias biológicas y culturales que integran su idea de nación colombiana.
} 
cuando negaban a los integrantes del estrato tradicional o empírico como sujetos creadores de cultura para justificar las desigualdades socioeconómicas. Por consiguiente, Zapata consideró que, tanto en el pasado como en el presente, la negación de la cultura era un patrón ideológico que le sirvió a un grupo para justificar sus privilegios sobre otros. Con respecto a este fenómeno en el siglo XX, afirma:

Los fenómenos de alienación extranjerizantes son más aparentes en científicos, arquitectos, ingenieros, médicos, psicólogos, historiadores, y en no pocos antropólogos. En general los profesionales dependientes de métodos, técnicas, herramientas de trabajo, etc., así como industriales y comerciantes, menosprecian su propia inventiva y la de su pueblo, para acogerse con mínimo o ningún esfuerzo creador, a la postura cómoda y pasiva de recibir, instrumentar y adecuar las necesidades del país a los últimos adelantos de la industria, la ciencia y el pensamiento científico de los grandes centros metropolitanos. (1974: 10)

Por otra parte, Zapata señala que estas actitudes alienantes también estaban presentes en los "mestizos", quienes habían interiorizado el valor negativo que se le adjudicó al mestizaje en la época colonial, lo que les había impedido reconocer su propia identidad y asumieron la misma conducta alienante del estrato académico o tecnológico de apropiarse de los patrones culturales extranjeros:

Alintroyectarse la mirada discriminadora del Conquistador, el mestizo aceptó inconscientemente la subvalorización a que fue sometido, considerando su hibridez como un lastre cultural. La respuesta sublimizada a este complejo se refleja en el ocultamiento de nuestra identidad y en la imitación desenfrenada de patrones culturales extraños. (1974: 10)

Por consiguiente, tanto el estrato académico o tecnológico como los mestizos, negaron la autenticidad y la originalidad de la cultura colombiana. Cabe destacar que Zapata consideraba a las "clases populares" como los únicos sujetos desalienados, debido a que consideraba que eran los únicos que no adoptaron las tecnologías y productos creados desde las metrópolis. Lo anterior presupone una idealización de estos grupos como aislados de la modernización y la sociedad de consumo:

Las clases populares, sobre todo las campesinas, han asumido una posición consustancialmente opuesta. Menos intervenidas por la sociedad de consumo, satisfacen sus necesidades vitales y espirituales a expensas de su laboriosidad y aprovechamiento de los recursos naturales que aún quedan a su disposición. (1974: 10)

De esta manera, Zapata Olivella caracterizó el pensamiento neocolonialista de los mestizos y del estrato académico o tecnológico como un pensamiento alienado, que llevó a una imitación desenfrenada de patrones culturales extranjeros y a la negación de la autenticidad de la cultura nacional colombiana. Grupos que tenían una actitud receptiva y no se esforzaban por crear o 
inventar. Cabe señalar que, como en su noción de literatura nacional, Zapata no era renuente a las influencias extranjeras sino que apostaba por un apropiación crítica y creativa a partir de las realidades y necesidades locales, de allí que considerara que la literatura nacional colombiana de la década de 1970 se caracterizó por una apropiación de las técnicas modernas narrativas aplicadas a los temas y los problemas nacionales.

Ante este pensamiento alienado, buscó en El hombre colombiano hacer una evaluación y un examen crítico de la autenticidad y originalidad de la cultura nacional colombiana. El conocimiento de estas realidades tenía que partir de una antropología cultural desalienada, antiracista y anticolonialista, por lo que en su introducción comenta que "Las apreciaciones que pudieran hacerse sobre la originalidad y la autenticidad de la cultura colombiana, habrán de basarse en el hecho universal de que el hombre, no importa cuáles sean sus herramientas, es un creador de nuevos valores" (Zapata Olivella, 1974: 9). Asimismo, esta antropología cultural tenía que analizar cómo las relaciones de dominación y dependencia entre países metropolitanos y periféricos implicaban ciertos contactos culturales e influencias ideológicas negadores de la cultura de los países periféricos, así como el papel de las élites intelectuales y políticas locales en la reproducción de estas relaciones de dominación, a través de la negación de las culturas de los estratos tradicionales y empíricos de sus naciones.

A partir de esta antropología descolonizadora, Zapata buscó afirmar la autenticidad de la cultura nacional colombiana. Cabe preguntarse: ¿Qué entendía por cultura nacional auténtica? ¿Una cultura resultado de un proceso histórico o en proceso de constitución?

La idea zapatiana de cultura nacional auténtica tiene dos acepciones: la primera consiste en afirmar que es una realidad histórica concreta, cuyas características definitorias son el mestizaje y la tradición (1974: 10); y la segunda sostiene que es una cultura en proceso de constituirse, cuya originalidad se basa en que tiene que partir de sus propias necesidades y realidades. Zapata precisa las diferencias entre la cultura nacional colombiana auténtica y la alienada de la siguiente manera:

En este campo de ideas el pueblo colombiano, ligado a una historia milenaria, a una ecología, a unas necesidades biológicas, constituye, como cualquier otro pueblo, una realidad creadora. $\mathrm{Su}$ originalidad no va más allá de satisfacer sus propias necesidades, a partir de la identidad entre su vivencia social y los recursos ecológicos de que dispone. Si su creación es distorsionada por factores intrínsecos o exteriores, obligándola a satisfacer necesidades superfluas o extrañas, es claro que desaparecería toda autenticidad y caería en los resortes de la alienación. (1974: 11)

Por consiguiente, Zapata Olivella llamaba a los colombianos a despojarse de su mentalidad neocolonialista a través del conocimiento de su autenticidad, es decir del reconocimiento de su mestizaje, sus tradiciones y de una conciencia crítica frente a la dominación cultural extranjera, lo que implicaba el reconocimiento de los africanos, indígenas, españoles y sus descendientes como sujetos creadores de la cultura nacional colombiana. Esta toma de conciencia llevaría a 
Roxana Ponce Arrieta

los colombianos a identificar cómo esa mentalidad colonialista que sirvió a los colonizadores para justificar la explotación del indígena y del africano, continuaba reproduciéndose en las élites colombianas, quienes minimizaban los aportes de los estratos tradicionales y empíricos para legitimar sus privilegios y sostener un orden económico desigual. Sobre su proyecto nacional, Zapata Olivella convocaba en los siguientes términos:

Afrontemos el hecho histórico de nuestro mestizaje como un presupuesto que puede ser el peldaño que conduzca a una real democracia cultural. Para ello es necesario vencer ocultos sentimientos que a veces perturban la conciencia para la comprensión lúcida de nuestra identidad étnica y cultural, y otras, para mantener cierto sistema de privilegios heredados de la colonia. (1974: 12)

En conclusión, Zapata Olivella sitúa el problema de la identidad nacional en el contexto de las relaciones de dependencia tecnológica de Colombia con los países metropolitanos y sus implicaciones culturales. A partir de una antropología desalienada ofrece una serie de conceptos para examinar estas relaciones de dominación cultural desde lo local a lo global, tales como neocolonización, cultura alienada, cultura auténtica y esquizofrenia cultural.

\section{La idea de nación y trietnicidad en El hombre colombiano}

En El hombre colombiano, Zapata Olivella no buscó examinar cómo un grupo de intelectuales y políticos construyó o inventó la nación colombiana, sino que pretendió ofrecer una explicación sobre su formación histórica. A partir de su presente se cuestionó sobre las influencias de las tecnologías y los medios de comunicación en las expresiones culturales tradicionales colombianas. De allí que consideró que la nación colombiana no era una realidad acabada, sino que continuaba creándose, pero que manifestaba fenómenos alienantes. Por ello se interesó en historizar la conformación de la nación para señalar que era resultado de una serie de mestizajes creativos y desalientantes, es decir, se preocupó por analizar las relaciones y las influencias entre nuevas tecnologías y la identidad cultural colombiana.

Para el escritor, la nación colombiana es un pueblo nuevo resultado de los mestizajes entre los tres troncos étnicos: uno originario que denominó "americano", y dos trasplantados que llamó "africano" y "español". Cabe señalar que, a pesar de que a lo largo del texto no existe ningún comentario o cita sobre la obra de Darcy Ribeiro, sino que solo en la parte de la bibliografía se menciona una de sus obras titulada Las Américas y la civilización, considero que los conceptos de pueblos nuevos y pueblos transplantados del antropólogo brasileño fueron recuperados en $E l$ hombre colombiano. Lo anterior se puede observar en la noción de troncos étnicos del autor que más adelante se examinará.

A lo largo del texto, Zapata Olivella deja entrever su noción de mestizaje como proceso histórico, biológico y cultural, que presupone una estrecha relación entre raza y cultura. Emplea el uso 
de categorías raciales cuando se refiere a los "tipos raciales" que conformaron la humanidad" y algunas nociones de trasmisión de la cultura a través de la herencia biológica. Por ejemplo, en la parte titulada "El tronco étnico africano" señaló como una de las características definitorias de los bantús su "permeabilidad", por lo que los consideró como los más aptos para el mestizaje en América (1974: 148). Aunque Zapata busca historizar el proceso de formación de la nación colombiana, continúa reproduciendo algunas ideas estáticas sobre la cultura, las cuales se explicarán más adelante con el concepto de "aportes psicoafectivos".

De acuerdo con Mara Viveros, Zapata Olivella elabora su concepto de trietnicidad para referirse al mestizaje como proceso histórico y cultural de intercambios culturales forzados de los sujetos y culturas que conformaron los tres troncos étnicos. Aunque fue influido por movimientos y discursos que valoraron positivamente al mestizaje, Zapata Olivella se distanció de las nociones de mestizaje como proceso mecánico, homogéneo y armónico, de allí que su noción se caracterizará por tres elementos: su heterogeneidad, conformada por la diversidad de pueblos y sujetos de los tres troncos étnicos; su conflictividad, debido a que hace énfasis en las condiciones y relaciones de poder en las que se dieron dichos intercambios; $y$, su historicidad porque señala que el mestizaje ocurrió antes de la venida de los europeos y africanos a América. Sobre la noción de trietnicidad, Viveros reflexiona:

Ahora bien, para Zapata Olivella el término mestizaje no hace alusión tan sólo a una "mezcla racial", sino también cultural, y por eso creó la denominación de trietnicidad para hacer referencia a esos intercambios culturales obligados que se dieron entre españoles, africanos e indígenas en el territorio colombiano según unas reglas de juego que determinaron que indios y esclavos fueran dominados y supeditados al "blanco". (Viveros, 2013: 91)

Si bien Zapata Olivella buscó historizar el proceso de formación de la nación colombiana, lo hizo desde la perspectiva del "colonizado" y no del "colonizador", debido a que no concibió a la nación colombiana como resultado de la asimilación, la imitación o la recepción pasiva de la cultura del "colonizador", sino como producto de una respuesta creativa y estratégica de los “colonizados". Por tanto, al igual que en su visión sobre la historia de la literatura nacional, Zapata cuestionó las visiones y periodizaciones de la historia relacionada con la presencia e influencias del colonizador y ofreció una periodización distinta a partir del reconocimiento de la presencia y las respuestas creativas de los colonizados. Es importante resaltar que en El hombre colombiano se materializaron algunas ideas sobre la nación que se venían desarrollando en Letras Nacionales, revista en la que nuestro autor vertió sus ideas sobre literatura nacional. Así, las ideas de Zapata

\footnotetext{
${ }^{7}$ El escritor se basa en la idea de que los antepasados de la humanidad actual eran cuatro tipos raciales, tres de ellos se desarrollaron en África y el restante en Europa. De acuerdo con su interpretación, en el momento del poblamiento de América ya se habían desarrollado los cuatro tipos raciales: "En los momentos actuales en que la evolución del hombre se concibe como una sola, constante y universal, el descubrimiento del indígena americano aparece como la culminación de un gran ciclo histórico que se había iniciado en la Edad Cuaternaria con la dispersión por el mundo de los cuatro tipos raciales conocidos: bosquimano, pigmeo, negro y caucásico" (Zapata,1974: 17). Cabe mencionar que a lo largo del texto se puede identificar una ambivalencia en el uso del término negro: por una parte, tiene un contenido cultural cuando hace referencia a la heterogeneidad cultural de los africanos y sus descendientes en África y América. En este sentido a veces usa negro como sinónimo de africano. Y, por otra parte, tiene un contenido biológico cuando habla de aportes psicoafectivos o cuando se le incluye en los "tipos raciales" del estrato tradicional, empirico o folclórico.
} 
Roxana Ponce Arrieta

sobre la periodización de la literatura nacional se pueden aplicar también a su concepto de cultura nacional:

Habitualmente se entiende entre nosotros por literatura nacional el proceso de asimilación de la foránea. Cuentan sólo las vicisitudes de las ideas ajenas en nuestro medio. De allí que se pretenda dividir la historia de la literatura nacional relacionada con aquellas. Los términos usuales de clasificación son harto conocidos: Descubrimiento, Conquista, Colonia, Independencia, Universalización. Tal pareciera que importara poco el fenómeno nacional ya que este, según ese razonar, no tiene existencia propia, sino conciencia receptiva, literatura parasitaria. La árida cara de un satélite que refracta luz prestada. Ya es tiempo de que al hablar del híbrido no solo se analice lo que recibimos de la literatura colonizadora sino también la respuesta de la colonizada. (Zapata, 2010: 187)

De esta manera, Zapata Olivella, a partir del concepto de mestizaje, historiza la conformación de la nación, establece sus orígenes, momentos embrionarios y constitutivos, define los grupos y sujetos nacionales. En oposición a las imágenes hegemónicas de la nación, en las tres primeras partes de El hombre colombiano sitúa los orígenes de la misma en el pasado civilizatorio de los tres troncos étnicos antes de la venida de los españoles a América en el siglo XV, y en la cuarta parte señala el momento constitutivo de la nación en el choque violento de los tres troncos durante la conquista y el período colonial.

De acuerdo con Zapata Olivella, el mestizaje es un proceso que no comenzó en el siglo XVI con el arribo de los europeos a América y la posterior llegada de los africanos, sino que arrancó desde los orígenes de cada uno de los tres troncos étnicos. Así reitera su idea de mestizaje como hecho universal de todas las culturas. En las tres primeras partes de su texto, el autor reconstruye los orígenes y la conformación histórica de los distintos pueblos que integran los tres troncos étnicos antes del s. XV. A pesar de que subraya las diferencias entre ellos, señala que estos troncos comparten tres características: su heterogeneidad, debido a que estuvieron constituidos por distintos grupos étnicos; su mestizaje conflictivo, debido a que estos grupos se conformaron a través de invasiones y colonización; y, finalmente, los intentos de unificación de los distintos grupos hacia el siglo XV.

En este punto, es interesante reflexionar acerca de cómo a partir de esta interpretación el autor se desmarca de algunas narrativas de la nación colombiana que negaron o subestimaron el pasado civilizatorio de los pueblos africanos que arribaron de manera forzada a Colombia. Actualmente existen autores, como Julio Arias, que sostienen que los africanos no fueron "invisibilizados" de las narrativas nacionales colombianas del siglo XIX, sino que fueron incorporados de manera marginal y estereotipada (2007: 50), ante lo cual considero que también Zapata Olivella cuestionó las narrativas hegemónicas de la nación y de algunos estudios históricos que reconocieron a los africanos como fuerza de trabajo esclavizada. En oposición los colocó como sujetos centrales que 
contribuyeron en la construcción de la identidad nacional colombiana.

En la siguiente tabla establezco lo que el autor considera como las características y los "aportes psicoafectivos" de cada tronco étnico a la constitución de la nación colombiana:

\begin{tabular}{|c|c|c|c|}
\hline $\begin{array}{c}\text { Características de los } \\
\text { troncos étnicos }\end{array}$ & Americano & Hispano & Africano \\
\hline Orígenes & $\begin{array}{c}\text { El poblamiento de América y } \\
\text { Colombia }\end{array}$ & $\begin{array}{l}\text { Cuatro periodos históricos de } \\
\text { conformación de los pueblos } \\
\text { hispanos. }\end{array}$ & $\begin{array}{l}\text { Origen de la humanidad y } \\
\text { poblamiento de África. }\end{array}$ \\
\hline Heterogeneidad & $\begin{array}{l}\text { Establece tres subestratos: } \\
\text { arawak, chibchas y caribes, } \\
\text { señala que se dieron distintos } \\
\text { mestizajes conflictivos que } \\
\text { dieron lugar a nuevos pueblos } \\
\text { "mestizos", entre los que } \\
\text { destaca: Quimbayas, Catíos, } \\
\text { Zenúes, Tayronas, Guajiros o } \\
\text { Guanes. }\end{array}$ & $\begin{array}{c}\text { Castellanos, asturianos, } \\
\text { valencianos, aragoneses, } \\
\text { navarros-leoneses, andaluces, } \\
\text { murcianos, canarios, } \\
\text { vascos, catalanes, gallegos y } \\
\text { extremeños. }\end{array}$ & $\begin{array}{l}\text { Yorubas, bantús, fantís, } \\
\text { ashantis, wolofs, } \\
\text { carabalíes, ewe-fons, } \\
\text { berberiscos y guineanos. }\end{array}$ \\
\hline Mestizaje conflictivo & $\begin{array}{l}\text { Cuestiona las tesis puristas } \\
\text { de algunos estudios de la } \\
\text { antropología colombiana } \\
\text { sobre estos grupos y señala } \\
\text { que tuvieron contactos e } \\
\text { intercambios conflictivos. }\end{array}$ & $\begin{array}{l}\text { Estos pueblos se configuraron } \\
\text { a través de conquistas, } \\
\text { invasiones y colonizaciones. }\end{array}$ & $\begin{array}{l}\text { Establece algunos } \\
\text { intercambios conflictivos } \\
\text { entre estos pueblos, por } \\
\text { ejemplo, los intercambios } \\
\text { entre bantús y yorubas. }\end{array}$ \\
\hline $\begin{array}{l}\text { Aportes psicoafectivos } \\
\text { a la nación colombiana }\end{array}$ & $\begin{array}{l}\text { Adaptación a distintos pisos } \\
\text { ecológicos. }\end{array}$ & Mesianismo. & $\begin{array}{c}\text { Optimismo, sensibilidad y } \\
\text { emoción. }\end{array}$ \\
\hline
\end{tabular}

Zapata Olivella buscó un examen de la "psicología” de los grupos étnicos colombianos actuales y los troncos étnicos de la nación. En su interpretación está implícita cierta esencialización y homogeneización de estos grupos, pues la noción de los "aportes psicoafectivos" de cada uno de los troncos étnicos supone una noción de la trasmisión de la cultura a través de la herencia. Si bien reconoce la diversidad cultural de cada tronco, el autor les adjudica ciertos comportamientos y conductas generales que fueron trasmitidas a sus descendientes mestizos y que consideró como contribuciones a la nación colombiana.

En la cuarta parte, titulada "La aculturación", Zapata Olivella establece el momento constitutivo de la nación en la conquista y la colonización de América: en estos dos acontecimientos fundacionales se dieron los choques e intercambios entre los pueblos de los tres troncos étnicos que originaron las distintas expresiones culturales que conforman la cultura nacional colombiana. Para explicar este proceso complejo de choques e imposición cultural, Zapata retoma tres conceptos: transculturación, aculturación y deculturación, que define de la siguiente manera:

En esta configuración táctica, podemos distinguir tres fenómenos: la transculturación de valores extracontinentales sumados a la cepa aborigen; la aculturación impositiva de los aportes indígenas, hispánicos y africanos; y la endoculturación de los mismos a partir de la creatividad 
del mestizo. Los dos primeros fueron "forzados" sobre la cultura sometida por el colonizador, en tanto que los últimos -endoculturados- pertenecen a lo que Bastide llama intercambios "libres", dentro de la relativa independencia de un país que ha sufrido la colonización. (Zapata, 1974: 178)

De acuerdo con lo anterior, Zapata resignificó el concepto de transculturación de Fernando Ortiz, quien define a la transculturación como las distintas fases del tránsito de una cultura a otra, en la que incluye la aculturación como la apropiación de una cultura, la desculturación como la pérdida parcial de la cultura precedente y la neoculturación como la creación de una nueva cultura. El antropólogo cubano lo explica de la siguiente manera:

Entendemos que el vocablo transculturación expresa mejor las diferentes fases del proceso transitivo de una cultura a otra, porque éste no consiste solamente en adquirir una distinta cultura, que es lo que en rigor indica la voz anglo-americana aculturación, sino que el proceso implica también necesariamente la pérdida o desarraigo de una cultura precedente, lo que pudiera decirse una parcial desculturación, y, además, significa la consiguiente creación de nuevos fenómenos culturales que pudieran denominarse de neoculturación. (Ortiz, 1978: 96)

A la luz de esta definición, Zapata concibe a la transculturación como la "suma" forzada de valores culturales de los tres troncos étnicos, mientras que la aculturación es esa imposición forzada de la cultura del colonizador a la de los "americanos" y africanos, y la endoculturación, la creación de una nueva cultura resultado de la aculturación y transculturación. Por consiguiente, el concepto de transculturación de Zapata se diferencia del de Ortiz debido a que no menciona la fase de desculturación y resalta la de aculturación. Asimismo, lo que entiende por endoculturación se asemeja a la fase de neoculturación que señala Ortiz.

En el proceso de mestizaje se tienen que tomar en cuenta dos elementos: los "valores culturales" y los factores (étnicos, históricos, ecológicos, económicos, sociales, políticos y religiosos). De allí que Zapata no hable de un mestizaje en abstracto sino de mestizajes concretos e históricos. Sobre la importancia de la segunda variable que influye en el mestizaje enfatiza que "Los factores que forzaron y fuerzan la amalgama cultural son tanto o más importantes que los mismos elementos entrelazados" (1974: 178). Y más adelante afirma: "Dentro de este gran marco, las fuerzas aglutinadas -étnicas, ecológicas, económicas, sociales, políticas, religiosas- han influido en distintos grados y presiones según el momento histórico" (1974: 182-183).

Por consiguiente, para entender la constitución de la conformación de la nación colombiana ofrece una periodización: una primera fase que ubica en la conquista y el s. XVI, a la que denomina aculturación hispánica e indígena, y luego apunta una fase final que abarca los demás siglos de la colonia, donde se da una triaculturación hispánica, americana y africana. Finalmente, el resultado de los intercambios de las dos fases dio lugar a lo que denominó la endoculturación "multirracial". Sobre la primera fase, comenta lo siguiente: 
La conquista y el primer siglo de la Colonia, se caracterizaron por la compulsión violenta que sufrió el indio -más concretamente la mujer indígena- en el proceso de hibridación étnica. A las muchas razones esgrimidas por el conquistador para desatar una guerra de exterminio, primero contra los varones caribes, posteriormente contra Zenúes, Tayronas, Quimbayas y Chibchas, debió influir en sumo grado el apetito sexual de la tropa hispánica que llegaba al Continente sin mujeres, tras la abstinencia de los largos días de navegación y con el erotismo que despertaban las narraciones de los primeros expedicionarios acerca de la fácil adquisición de indígenas. $(1974: 183)^{8}$

Además, en lo que respecta a la triaculturación, hace hincapié en las relaciones de dominación entre grupos subalternos. Para ello, retoma como ejemplo la región de lo que actualmente es el Pacífico colombiano, donde expone una serie de casos en los que los africanos "bozales" libres, zambos y cimarrones ejercieron violencia contra los indígenas. En este marco señala que no sólo los africanos les robaron tierras y sus mujeres, sino también se apropiaron de la cultura de los indígenas. Habrá que profundizar la importancia de señalar esta tesis del autor en la década de los 70's, debido a que tiene una visión crítica sobre la participación de los africanos y sus descendientes no sólo como víctimas de la trata negrera y la esclavización, sino también como sujetos que agredieron físicamente a los "indígenas", ya sea como instrumentos de represión del colonizador contra el "indígena" o como cimarrones, como sucedió en esta región:

Los cimarrones debieron constituir para el indígena elementos excesivamente expoliadores. Llegaban desprovistos de recursos colonizadores, desnudos hambrientos y dispuestos a quedarse definitivamente en las zonas selváticas disputadas. Para afirmar su nueva economía de libertos, esta conjunción de negros e indios sin la intervención directa del hispano o del criollo, requirió al menos en los primeros momentos que los cimarrones arrebataran al indígena sus mujeres, la tierra, labranzas, técnicas empíricas y no pocos hábitos sociales. [...] Una vez que se trataba de una conquista en la que el negro perseguía ya no imponer sus valores culturales, sino tomarse a la fuerza los del indígena, obligándolo a que los fundiera con los suyos. (1974: 190)

De esta manera, Zapata aporta a la reflexión de las relaciones de dominación entre los propios sujetos subalternos y los mestizajes que ocurrieron en estos contextos.

El autor caracterizó la aculturación como un proceso donde los colonizados tuvieron una participación creativa, táctica y estratégica frente a los valores impuestos por el colonizador, al mismo tiempo que enfatizó su carácter violento y conflictivo. En oposición a las tesis sobre la cultura nacional colombiana como resultado de una simple asimilación o imitación de la cultura hispana, Zapata afirma su autenticidad y originalidad por la creatividad de los miles de africanos e "indígenas" que resignificaron y recrearon la cultura del colonizador. Para sostener esta tesis central

\footnotetext{
${ }^{8} \mathrm{La}$ violencia hacia las mujeres indígenas es una de las tesis centrales sobre este primer mestizaje que denominó aculturación hispano-indígena. En mi investigación de maestría intentaré responder: ¿Cuál es la interpretación de Manuel Zapata Olivella en El hombre colombiano sobre el papel de las mujeres "indígenas", africanas y españolas en la construcción de la nación colombiana?
} 
Roxana Ponce Arrieta

se vale de lo que denomina tres leyes de la dinámica de la cultura: la acumulación, la transmisión y la modificación. Desde mi perspectiva, Zapata se basa en la segunda ley para examinar los distintos mecanismos de trasmisión de las culturas donde ocurrió la creatividad de los colonizados, mecanismos a los que introduce y clasifica de la siguiente manera:

Este proceso está regido por ciertos mecanismos estudiados ampliamente por antropólogos como Bastide, mecanismos que podemos clasificar así:

a) Las culturas enfrentadas actúan como conjuntos, aunque la asimilación de los valores extraños se realiza de individuo a individuo.

b) La aceptación o rechazo asumidos por el receptor ante los nuevos patrones obedece a procesos racionales, aunque carezca de sentido para el colonizador.

c) La resistencia a asimilar un patrón extraño se debe a dos causas: el enfrentamiento de dos tradiciones distintas, y al hecho de que un sistema amenaza la existencia del otro.

d) Mientras más extraño sea el rasgo cultural del agresor más resistencia encontrará el aculturado.

e) Los valores foráneos son más fácilmente asimilados por su forma que por sus funciones; los nuevos valores introducidos deben cumplir en el pueblo conquistado similares objetivos a los que llenaba en su cultura de origen. (1974: 180)

En suma, Zapata definió a partir del mestizaje los orígenes y los momentos constitutivos de la nación, donde reconoció a los americanos, africanos, españoles y sus descendientes como sujetos culturales que contribuyeron a la construcción de la nación, desde sus orígenes hasta su conformación, es decir los colocó en términos temporales en el pasado de la nación.

Después de analizar estos dos momentos, cabe preguntarse: ¿cuáles son los grupos o sujetos que integran la nación colombiana en el presente de la escritura de El hombre colombiano? ¿Cuál era el futuro de estas diferencias culturales? Es decir, ¿Zapata proponía su integración o su eliminación?

Para Zapata Olivella, la nación colombiana estaba integrada por una heterogeneidad de grupos y sujetos. A estas diferencias las divide en tres grupos: los estratos sociales (el académico o tecnológico y el tradicional, empírico o folclórico), los nueve grupos étnicos (antioqueño, cundiboyacense, tolima-huilense, santandereano, costeño, caucano, andino-sureño, llanero-oriental e isleño) y los "tipos raciales" ("mestizos triétnicos", "indígenas", "negros", "mulatos" y "zambos"). De acuerdo con Alfonso Múnera, la idea de nación de este intelectual afrocolombiano es una de las primeras que reconoce no sólo su diversidad sino también el papel creador de "indígenas" y de los descendientes de africanos desde la primera mitad del siglo XX: 
Y es quizás el único de nuestros intelectuales que a mediados del siglo XX piensa a la nación como un todo, integrado por fuerzas creativas heterogéneas, en las que afros y nativos juegan un papel central que reconoce la extraordinaria diversidad de su cultura, y que denuncia de manera brillante los mecanismos de imposición de una historia y unos valores culturales colonialistas. (Múnera, 2010: 15-16)

Desde mi perspectiva, este intelectual afrocolombiano no buscó una integración o eliminación de las diferencias culturales de "indígenas" y de los descendientes de africanos a través del mestizaje, como sí lo hicieron muchas ideologías del mestizaje, sino que pensaba que se tenían que reconocer sus contribuciones culturales en el pasado y en el presente de la nación. Para el caso de los indígenas sugirió el respeto de su autonomía: "En la medida en que le reconozcamos sus derechos para autodeterminarse como hombres libres dentro de la integridad nacional, recibiremos en buena hora, sus nuevos y refrescantes aportes" (1974: 12). Para el caso de los descendientes de africanos buscó su reconocimiento histórico como sujetos de la nación colombiana. Hay que enfatizar que en este momento histórico no se pensaba en una inclusión jurídica a la Constitución de las diferencias culturales étnicas y urbanas afrocolombianas, negras, palenqueras y raizales, sino que esto sucedería recién a fines del siglo XX.

Zapata Olivella proponía el reconocimiento del mestizaje como un camino a la igualdad cultural y racial. Esto implicaba la afirmación del papel creativo de "indígenas" y "negros" y la identificación de los usos ideológicos de la negación de sus culturas para justificar los privilegios de unos cuantos grupos, tanto en el pasado colonial como en el presente. Por ello apelaba a la toma de conciencia de esta identidad mestiza para revertir estas desigualdades sociales resultado de un pasado colonial:

El futuro de nuestro país, no será el resultado de un determinismo histórico, al margen de nuestra conciencia y voluntad. Muy poco contribuiríamos a lograr un verdadero equilibrio racial y cultural, si persistiéramos en ignorar que conformamos un pueblo híbrido con desigualdades sociales en virtud de la herencia colonial. El deber es apersonarnos de esta realidad y aprovecharnos de sus inmejorables ventajas. Para ello, desde luego, es necesario reconocer la participación creadora de indios, hispanos y negros en nuestra cultura. (Zapata, 1974: 13)

\section{CONCLUSIONES}

El lugar marginal de los estudios sobre los ensayos antropológicos de Manuel Zapata Olivella responde a una serie de políticas de conocimiento y prácticas académicas, entre las que destaqué la trivialización de sus argumentos antropológicos y la periferización de lo afrodescendiente. Las múltiples facetas de este escritor, antropólogo, gestor cultural y activista político es un claro ejemplo del dinamismo, la complejidad y el activismo de las figuras intelectuales "negras", afrocolombianas y afrodescendientes en América Latina, debido a que sus procesos intelectuales están en constante diálogo con las transformaciones políticas y económicas de sus países y de la región. 
Roxana Ponce Arrieta

La redefinición de la nación en El hombre colombiano se sitúa en el marco de las relaciones de dependencia de Colombia con los países metropolitanos, cuyas influencias en el terreno cultural son analizadas y conceptualizadas por Zapata Olivella. Entre los conceptos que se examinaron están: neocolonización, esquizofrenia cultural, cultura nacional alienada y auténtica. Este artículo buscó profundizar en dos nociones centrales: la nación y la trietnicidad. Además, enfaticé en cómo Zapata reconoció que la autenticidad de la nación colombiana no sólo se basaba en el mestizaje y la tradición, sino también en una realidad cultural a constituirse a partir de sus propias necesidades y realidades.

Desde el mestizaje, este intelectual señaló los orígenes y los momentos constitutivos de la nación, asimismo afirmó el papel creativo de "indígenas", africanos y sus descendientes en la construcción de la nación como una estrategia que permitiría identificar la mentalidad alienada neocolonial de los distintos estratos de la nación colombiana. En otras palabras, invitaba a los colombianos a descolonizar y desalienar su pensamiento como primer paso para revertir las desigualdades culturales, económicas y sociales heredadas por el colonialismo.

\section{BIBLIOGRAFÍA}

Arboleda Quiñones, S. (2011). Le han florecido nuevas estrellas al cielo: suficiencias íntimas y clandestinización del pensamiento afrocolombiano. Programa de Estudios Culturales, Universidad Andina Simón Bolívar.

Arboleda Quiñones, S. (2010). El mestizaje radical de Manuel Zapata Olivella: raza, etnia y ciudadanía. En: Mosquera Rosero-Labbé, C.; Laó-Montes, A.; Rodríguez Garavito, C. (editores y coautores). Debates sobre ciudadanía y políticas raciales en las Américas Negras (pp. 441-461). Bogotá: Universidad Nacional de Colombia.

Arias Vanegas, J. (2007). Nación y diferencia en el siglo XIX colombiano. Orden nacional, racialismo y taxonomías poblacionales. (Tesis de maestría). Bogotá: Universidad de los Andes, Facultad de Ciencias Sociales-CESO, Departamento de Antropología.

Caicedo Ortiz, J. A. (2013). A mano alzada... Memoria escrita de la diáspora intelectual afrocolombiana. Popayán: SentiPensar Editores.

Oliva, E. (2017). Intelectuales afrodescendientes: apuntes para una genealogía en América Latina. Tabula Rasa, (27), 45-65. Recuperado de: http://www.revistatabularasa.org/numero-27/04oliva.pdf

Ortiz, F. (1978). Contrapunteo cubano del tabaco y el azúcar. Caracas: Biblioteca Ayacucho. 
Palacios, G. (2015). Apuntes sobre la música, el folclor, lo nacional-popular y la literatura en algunos de los estudios tempranos de Manuel Zapata Olivella. Escritos, 23(51), 439-470. Recuperado de http://www.scielo.org.co/pdf/esupb/v23n51/v23n51a07.pdf

Valero, S. (2013). ¿De qué hablamos cuando hablamos de "literatura afrocolombiana"? O los riesgos de las categorizaciones. Estudios de Literatura Colombiana, (32), 15-37. Recuperado de https://www.researchgate.net/publication/277653546_De_que_hablamos_cuando_ hablamos_de_literatura_afrocolombiana_O_los_riesgos_de_las_categorizaciones

Velandia, P. J.; Restrepo, E. (2017). Estudios afrocolombianos: balance de un campo heterogéneo. Tabula Rasa, (27), 161-197. Recuperado de http://www.revistatabularasa.org/numero-27/08velandia.pdf

Viveros Vigoya, M. (2013). Mestizaje, trietnicidad e identidad negra en la obra de Manuel Zapata Olivella. En Restrepo, E. (Ed.) Estudios afrocolombianos hoy: aportes a un campo transdisciplinario (pp. 87-104). Popayán: Universidad del Cauca.

Zapata Cortés, D. C. (2009). Entre danzas, tambores y rezos: somos colombianos. Representaciones del "negro" en la obra folclórica de Manuel y Delia Zapata (1950-1970). (Tesis de pregrado). Bogotá: Facultad de Ciencias Sociales, Universidad de los Andes.

Zapata Olivella, M. (2010). Por el sendero de sus ancestros: Textos escogidos (1940-2000). Recopilación y prólogo de Alfonso Múnera, Tomo XVIII, Bogotá: Biblioteca de Literatura Afrocolombiana, Ministerio de Cultura.

Zapata Olivella, M. (1993). Enciclopedia audiovisual de la identidad colombiana: las múltiples caras del hombre colombiano: su lengua, su historia, su filosofia, sus costumbres y sus artes en un solo rostro, Vol. 2. Bogotá: Fundación Colombiana de Investigaciones Folclóricas.

Zapata Olivella, M. (1974). El hombre colombiano. Bogotá: Enciclopedia del Desarrollo Colombiano, Colección Los Fundadores, Vol. 1. 